\title{
Ethylene Hydrogenation Catalysis on Pt(111) Single-Crystal Surfaces Studied by Using Mass Spectrometry and In-Situ Infrared Absorption Spectroscopy
}

Aashani Tillekaratne, Juan Pablo Simonovis, and Francisco Zaera

\begin{abstract}
The catalytic hydrogenation of ethylene promoted by a $\operatorname{Pt}(111)$ single crystal was studied by using a ultrahigh-vacuum surface-science instrument equipped with a so-called high-pressure cell. Kinetic data were acquired continuously during the catalytic conversion of atmosphericpressure mixtures of ethylene and hydrogen by using mass spectrometry while simultaneously characterizing the surface species in operando mode by reflection-absorption infrared spectroscopy (RAIRS). Many observations reported in previous studies of this system were corroborated, including the presence of adsorbed alkylidyne intermediates during the reaction and the zero-order dependence of the rate of hydrogenation on the pressure of ethylene. In addition, the high quality of the kinetic data, which could be recorded continuously versus time and processed to calculate time-dependent turnover frequencies (TOFs), afforded a more detailed
\end{abstract}


analysis of the mechanism. Specifically, deuterium labeling could be used to estimate the extent of isotope scrambling reached with mixed isotope-substituted reactants $\left(\mathrm{C}_{2} \mathrm{H}_{4}+\mathrm{D}_{2}\right.$ and $\mathrm{C}_{2} \mathrm{D}_{4}+$ $\mathrm{H}_{2}$ ). Perhaps the most important new observation from this work is that, although extensive H-D exchange takes place on ethylene before being fully converted to ethane, the average stoichiometry of the final product retains the expected stoichiometry of the gas mixture, that is, four hydrogen atoms per ethane molecule in the case of the experiments with $\mathrm{C}_{2} \mathrm{H}_{4}+\mathrm{D}_{2}$. This means that no hydrogen atoms are removed from the surface via recombination to produce $\mathrm{X}_{2}(\mathrm{X}$ $=\mathrm{H}$ or $\mathrm{D})$. It is concluded that, under catalytic conditions, hydrogen surface recombination is much slower than ethylene hydrogenation and H-D exchange.

Keywords: Olefin Hydrogenation, Transition Metal Catalyst, Mass Spectrometry, Infrared Absorption Spectroscopy, Deuterium Labeling, Kinetics

\section{Introduction}

The hydrogenation of olefins is one of the oldest catalytic processes ever reported, going back as far as 1897 [1;2], yet it is still quite prominent in many industrial applications, in oil refining and in the food industry to name a few. The basic reaction mechanism for this reaction was proposed many years ago by Horiuti and Polanyi, who suggested that the surface of the metal used as catalyst facilitates the dissociation of molecular $\mathrm{H}_{2}$ into atomic hydrogen so that the adsorbed olefin then can incorporate such $\mathrm{H}$ species in a series of stepwise and reversible steps, to first form an alkyl surface intermediate and ultimately the final alkane [3]. This idea still offers the 
basic framework to explain olefin hydrogenations as well as olefin isomerizations (double bond migration, cis-trans interconversion [4]), yet it overlooks some subtleties that make the full understanding of the performance of this catalysis elusive [5-9].

Issues still unresolved in the mechanistic description of the hydrogenation of olefins by transition metals include the sensitivity of the conversion to the structure of the surface and the role of the carbonaceous deposits that form on the surface $[6 ; 8 ; 10-12]$. Studies with model systems and modern surface-sensitive techniques from many research groups have been directed to answer these questions $[7 ; 9 ; 13-20]$. Our laboratory in particular has been dedicated to this problem for a number of years, focusing, like many others, on the study of the prototypical case of the hydrogenation of ethylene on $\operatorname{Pt}(111)$ single-crystal surfaces [10; 21-41]. Much progress has been made, but key questions remain unanswered. At present, we are focusing on elucidating the participation of the hydrocarbon species strongly adsorbed on the surface, which in the case of ethylene conversion consists of ethylidyne moieties, in the catalytic conversion [8; 10], and on determining the effect that those may have on the kinetics of molecular hydrogen adsorption and activation.

Toward that end, we have developed an instrument for the operando study of catalytic reactions based on the idea of the so-called high-pressure cell, which is incorporated into the ultrahigh vacuum (UHV) equipment used for surface preparation and characterization in order to afford great control of the state of that surface before, during, and after catalysis via the ability to directly transfer it between the vacuum and catalytic environments without exposure to the outside atmosphere [42-46]. We rely on the use of infrared absorption spectroscopy in a single 
reflection mode (reflection-absorption infrared spectroscopy, or RAIRS [47-49]) for the in-situ characterization of the adsorbed species during reaction, and on the continuous analysis of the gas phase using mass spectrometry to obtain kinetic data [41]. Below we provide some examples of the type of data obtained with this apparatus, discuss its advantages, and indicate the approach to be taken to address the questions mentioned above. We also include some new results from studies using isotope labeling that point to the relative slow nature of hydrogen recombination on the metal surface under catalytic conditions compared to the ethylene hydrogenation and H-D exchange steps. This is a surprising result, because hydrogen recombination is known to take place readily on clean surfaces [50-53] and to be key to the behavior of transition metals as catalysts in many hydrogenation processes [6; 54-56].

\section{Experimental}

The experiments were carried out in a two-tier stainless-steel apparatus described in more detail elsewhere [41; 57]. The main chamber is kept under UHV by using a cryogenic pump, and is equipped with a UTI 100C quadrupole mass spectrometer interfaced to a computer to afford the continuous monitoring of the partial pressures of up to 15 masses in a single run. This mass spectrometer is typically used for temperature programmed desorption (TPD) experiments, but in the work reported here it was mainly employed to follow the kinetics of catalytic reactions, as discussed below. The UHV chamber is used for cleaning (with an ion sputtering gun) and for characterization of the sample, a $\operatorname{Pt}(111)$ single crystal of about $1 \mathrm{~cm}$ in diameter. The crystal is mounted on a manipulator capable of cooling to liquid-nitrogen temperatures and of resistive 
heating to up to $1100 \mathrm{~K}$ and used to transfer it between the two tiers of the system, namely, between UHV and the catalytic reactor.

The reactor volume of our instrument is usually connected to the UHV side, but contains a small retractable cell that can be sealed around the crystal to isolate it from the rest of the apparatus and pressurized to atmospheric pressures in order to carry out catalytic reactions. Two gas openings, the inlet directly facing the single-crystal surface and the outlet placed at the back of the cell, are used together with a closed loop and a bellows gas pump to circulate the reaction mixture around the catalyst, in an arrangement that makes our instrument behave as a continuously-stirred tank reactor (CSTR). The cell is also equipped with two $\mathrm{NaCl}$ windows on opposite sides that, in the closed position, become aligned with two additional windows in the side chamber to allow for the focusing of an infrared beam in and out of the Pt surface. The light is directed at a grazing incidence angle to be able to perform reflection-absorption infrared spectroscopy (RAIRS) experiments. The gases from a controlled leak from the closed cell into the main UHV chamber are analyzed with the mass spectrometer continuously during reaction to acquire the kinetic data.

The RAIRS data were acquired by using a Bruker Equinox 55 FT-IR spectrometer [58]. In our setup, the IR beam is extracted from the inside of the FT-IR instrument, directed through a polarizer and the $\mathrm{NaCl}$ windows on one side of the high-pressure cell, and focused through onto the sample at grazing incidence $\left(\sim 85^{\circ}\right)$. The reflected beam is then collected, after traveling through a second set of $\mathrm{NaCl}$ windows, onto a narrow-band mercury-cadmium-telluride (MCT) detector. Most spectra for the species adsorbed on the platinum surface are averages from 2000 
scans taken at a resolution of $4 \mathrm{~cm}^{-1}$, a process that takes about 4 min per experiment, and ratioed against spectra from the clean sample obtained in the same way before gas dosing. However, in order to be able to perform kinetic measurements in a timely manner, the data for the analysis of the gas-phase species reported in Figure 3 correspond to averages of only 64 scans; the lower number of scans afforded the collection of more spectra in less time (the strong signals from the gas-phase species do not require much signal averaging). The final RAIRS traces for the surface species were obtained by subtracting data obtained using s-polarized light from similar spectra recorded with p-polarized radiation in order to eliminate most of the contribution from the gasphase species (a small residual signal is still seen in some spectra, as indicated below).

For the typical experiments reported here, the Pt surface was first cleaned by sputteringannealing and oxygen treatments until the reported RAIRS spectra of a saturated layer of carbon monoxide on clean $\operatorname{Pt}(111)$ could be reproduced. Afterwards, the sample was transferred to the side chamber, and background RAIRS data acquired with both s- and p-polarized light. The Pt was exposed to the desired gases if a pretreatment was required (typically propylene, $\mathrm{C}_{3} \mathrm{H}_{6}$, $>99 \%$ purity from Matheson; see below), a new set of RAIRS acquired, the high-pressure cell closed, and yet another pair of RAIRS traces recorded. The crystal was then heated to the desired temperature by using a homemade power supply with a feedback loop that uses the temperature reading from a chromel-alumel thermocouple spotwelded to the side of the metal, and the reaction mixture, premixed in a side gas manifold and typically consisting of 2 Torr of ethylene $\left(\mathrm{C}_{2} \mathrm{H}_{4}, 99.5 \%\right.$, from Matheson, or $\mathrm{C}_{2} \mathrm{D}_{4}, 99 \% \mathrm{D}$ purity, from Cambridge Isotope Laboratories) and 50 Torr of hydrogen $\left(\mathrm{H}_{2},>99.995 \%\right.$ purity, from Liquid Carbonic, or $\mathrm{D}_{2}$, $>99.5 \%$ atom purity, from Matheson), let into the reaction volume. The gas composition was 
monitored continuously with the mass spectrometer until the reaction reached completion, after which the volume of the reactor was pumped with a turbomolecular pump and the cell retracted to expose the crystal back to the UHV environment. RAIRS spectra were taken during the course of the catalytic conversion as well as immediately before and right after opening the cell.

\section{Results}

Our ability to follow the kinetics of the catalytic hydrogenation reaction by mass spectrometry (MS) was tested first. Complete mass spectra of the gas mixture present in the high-pressure cell used as the reactor were taken at different stages throughout the conversion to analyze its composition. An example of the data acquired this way is provided in Figure 1. The massspectrometry traces evolve over time, indicating the consumption of the reactant (ethylene) and the accumulation of the product (ethane): notice in particular the growth of the peaks at 29 and $30 \mathrm{amu}$ typical of $\mathrm{C}_{2} \mathrm{H}_{6}$ with reaction time. Deconvolution of these spectra using the cracking patterns of the two main organic molecules (ethylene and ethane) can be used to extract quantitative information on the composition of the gas $[59 ; 60]$, and with that the extent of the catalytic conversion. The data in Figure 1 also help corroborate that there are no other major products or compounds in the gas mixture at any time during the catalytic runs.

Once all of the components of the gas mixture have been determined, the kinetics of the catalytic reactions can be better followed continuously by recording the signal intensities of selected MS peaks versus time. These peaks are chosen to best represent the species of interest, picking the 
masses that best achieve the compromise of displaying reasonable signals for a given species and minimum interference from all others. In the system studied here that can be easily achieved by selecting the 29 or 30 amu signals to represent ethane, since those display no interference from ethylene, and the 26 or 27 amu signals to follow the evolution of ethylene, after subtracting the contributions to those masses due to ethane. In fact, given that our instrument can follow up to 15 masses in the same run with a time resolution in the sub-second range, several peaks can be chosen for each compound to have the problem over-defined and to be able to use the redundancies to check on our signal deconvolution procedure.

Figure 2 illustrates this approach. The left panel shows the raw data recorded for 26, 27, 29, and $30 \mathrm{amu}$ during the course of a typical ethylene hydrogenation reaction. The accumulation of ethane over time in our high-pressure cell is evidenced by the approximately linear increases in the traces for 29 and $30 \mathrm{amu}$, until those reach their limit after approximately $230 \mathrm{~s}$, when the reaction reaches completion. The consumption of ethylene is less evident from the data, but can still be seen in the decrease in signal intensity in the 26 amu trace; the one for 27 amu shows little change because of a serendipitous cancellation of the contributions from the two molecules. The sharp transitions at the start and end of the reaction can also be taken as an indication that the gas in our reactor is well mixed and that the combined time constant for the system, including gas transport and instrument response times, is fast, on the order of a second or less.

The raw kinetic data can be deconvoluted to reflect the time evolution of the partial pressures of the reactants and products in the gas mixture using a well-established procedure described elsewhere [59], and then converted into turnover numbers (TON, number of molecules 
consumed or produced per Pt surface atom) by simple calibration involving the conversion of the MS signals to pressures and the measurement of the volume of the reactor and the surface area of the Pt crystal. The result of this analysis for the example in Figure 2, using the signals from the 26 and 30 amu peaks for $\mathrm{C}_{2} \mathrm{H}_{4}$ and $\mathrm{C}_{2} \mathrm{H}_{6}$, respectively, is shown as continuous (and smoothed) lines in the center panel. Again, approximately linear consumption of the reactant and accumulation of the product is seen throughout the catalytic run, all the way to completion, a reflection of kinetics with pseudo-zero-order in ethylene. It should be noted that in these experiments we have used a large excess of hydrogen in the reaction mixture so that the kinetics is not influence by changes in the pressure of that gas. Under the specific conditions of the experiment reported in Figure 2, the consumption of all of the ethylene provided requires a total of approximately 1000 turnovers.

Given that our kinetic runs are carried out in batch mode, the original time-dependent data correspond to changes in the total partial pressure of the gases, or to the integrated consumption of the reactants and accumulation of the products. Reaction rates can be extracted from those data by taking their numerical derivative versus time. The result of this operation is a set of traces of reaction rates (in turnover frequencies, $\mathrm{TOF}=\mathrm{TON} / \mathrm{s}$ ) versus time, as shown in the right panel of Figure 2. It can be seen there that, within experimental errors, the rates of the evolution of $\mathrm{C}_{2} \mathrm{H}_{4}$ and $\mathrm{C}_{2} \mathrm{H}_{6}$ mirror each other. The negative values for ethylene reflect its consumption, and the additional noise associated with the trace for ethylene is the result of the interference in the deconvolution of the 26 amu signal from ethane. The rates measured here for the hydrogenation of ethylene to ethane promoted by $\operatorname{Pt}(111)$ are approximately constant over most of the extent of the reaction, again reflecting the zero-order kinetics mentioned above (the 
spike toward the end of the reaction may be an experimental artifact, but more experiments are required to settle this issue). It is worth highlighting that, thanks to our ability to continuously monitor the gas composition throughout the catalytic conversion with good time resolution, it is possible to extract information on the time dependence of the reaction rates; this is not easy with the more common experimental setups that rely on the use of gas chromatography for the analysis of the reaction mixture (a common approach $[13 ; 42 ; 61-64])$.

The evolution of the composition of the gas-phase mixture during catalytic reactions was also evaluated in situ by infrared absorption spectroscopy. Our RAIRS system is designed to detect adsorbed surface species, the signals of which are enhanced by subtracting the spectra obtained using p- minus s-polarized light. For this, we take advantage of the well-know selection rule that applies to metal surfaces, which indicates that while absorption of infrared photons by gas molecules is isotropic and yields similar spectra regardless of the polarization angle of the excitation light, absorption by surface species is only possible with p-polarized light $[47 ; 49 ; 65$; 66]. In addition, though, the spectra taken with either polarization also contain information about the gas-phase species, which in fact are present in much higher concentrations within the path of the IR beam and therefore dominate the data. This is illustrated in Figure 3, which displays both p- and s-polarized IR spectra for different times during a catalytic run for the conversion of ethylene to ethane. First, it is clear that both set of spectra look quite similar, as expected. In addition, they only show peaks associated with gas species (in the intensity scale used in the figure); the absorption features from adsorbed species, which would be visible in the p-polarization only, are too small to be observed here. 
The peak assignment of the data in Figure 3 is quite straightforward. At the start of the reaction, $\mathrm{t}=0 \mathrm{~min}$ (top green traces), the gas only contains ethylene (and hydrogen), as indicated by the approximately 850 - 1100, $1400-1500,1850-1950$, and $2900-3200 \mathrm{~cm}^{-1}$ vibration-rotation manifolds of the $\mathrm{CH}_{2}$ out-of-plane deformation, the $\mathrm{CH}_{2}$ in-plane scissoring, an overtone, and the $\mathrm{C}-\mathrm{H}$ stretching motions of free ethylene molecules, respectively [67]. Conversely, after long reaction times $(\mathrm{t}=10 \mathrm{~min}$, bottom red traces), the gas only contains ethane, and the spectra only show the peaks at $\sim 750-950,1350-1550$, and $2850-3050 \mathrm{~cm}^{-1}$ for the $\mathrm{C}-\mathrm{C}$ stretching, $\mathrm{CH}_{3}$ deformation, and $\mathrm{C}-\mathrm{H}$ stretching vibrational modes of ethane. The integrated intensities of representative peaks for those species can then be used to quantify the gas composition at any point during the catalytic conversion of ethylene to ethane. The results from such analysis, using the integrated 930 - 970 and $2850-2900 \mathrm{~cm}^{-1}$ IR signals intensities for ethylene and ethane, respectively, are included as filled symbols in the central panel of Figure 2. Clearly, this is a much more cumbersome and less accurate method for kinetic measurements than the mass spectrometry detection discussed above, but was included here to provide confirmation of the performance of the mass spectrometry method and the simple composition and well-mixed nature of the gas in the reactor.

RAIRS spectra of the species adsorbed on the platinum surface during reaction (p- minus spolarized data) are reported in Figure 4. These data are similar to those reported by us [41; 68] and others $[17 ; 69 ; 70]$ in the past. The main feature seen in the $1000-1800 \mathrm{~cm}^{-1}$ window is the symmetric (umbrella) mode of the methyl group of ethylidyne, a surface species that forms on $\mathrm{Pt}(111)$ readily upon exposure of the clean surface to ethylene at temperatures around $300 \mathrm{~K}$, at about $1340 \mathrm{~cm}^{-1}[32 ; 71-74]$. Thanks to spectroscopic studies carried out in situ during reaction, 
it is also well known that this ethylidyne layer is present on the surface throughout the catalytic cycle for ethylene hydrogenation $[16 ; 17 ; 41 ; 70]$. Notice from the data in Figure 4 that the coverage of this species during reaction is significantly lower than saturation, which corresponds to a quarter of a monolayer (one ethylidyne moiety per four platinum surface atoms). In addition, the IR frequency shifts slightly over time.

The time evolution of these two parameters, namely, the peak intensity (converted to surface coverage) and the peak position, is summarized in Figure 5. A decrease in ethylidyne coverage during ethylene hydrogenation catalysis has been reported before [16; 41; 69], and in this case is not too surprising given that our reaction mixture is quite rich in hydrogen and that it is known that ethylidyne can indeed be hydrogenated, albeit slowly, by exposing it to atmospheric pressures of hydrogen $[14 ; 59 ; 75 ; 76]$. The peak shift has also been reported by us before [41], and may be due to differences in local environment on the surface as a result of the adsorbates in equilibrium with the high pressures of the surrounding gases. Alternatively, recent theoretical calculations also report a blue shift in vibrational frequency for this umbrella mode with decreasing ethylidyne coverage (from $1326 \mathrm{~cm}^{-1}$ at $1 / 3$ of a monolayer to $1330 \mathrm{~cm}^{-1}$ at $1 / 9$ of a monolayer) [77], a trend consistent with our data. One additional observation from Figure 4: there is often a broad, undefined peak seen in the $1410-1480 \mathrm{~cm}^{-1}$ region of the IR spectra during reaction. We believe that this feature arises from incomplete cancellation of the IR absorption from the gas species (ethylene and ethane) when subtracting the raw data recorded with p- minus s-polarized light; it goes away almost completely upon pumping of the highpressure cell. 
Finally, Figures 6 and 7 report kinetic data for experiments similar to those in Figure 2 but by using mixed isotopes: Figure 6 corresponds to a mixture of $\mathrm{C}_{2} \mathrm{H}_{4}+\mathrm{D}_{2}$, whereas Figure 7 was obtained by using $\mathrm{C}_{2} \mathrm{D}_{6}+\mathrm{H}_{2}$. Following the way the results were reported in Figure 2, the left panel of Figures 6 and 7 display the time dependence of the raw mass spectrometer signals, in these cases for all the masses in the range from 26 to 36 amu. These are needed to extract information not only for the rates of hydrogenation (or deuteration) of ethylene but also for the accompanying H-D exchange steps that take place on ethylene before full conversion to ethane. The time evolution of all the possible isotopologues of ethane, extracted by deconvolution of those raw data [31; 59], is shown in the corresponding central panels of the Figures 6 and 7. Virtually no exchanged ethylene molecules were detected at any stage of the reaction: a small amount of $\mathrm{C}_{2} \mathrm{H}_{3} \mathrm{D}$ appears to build up in the early stages of the conversion of the $\mathrm{C}_{2} \mathrm{H}_{4}+\mathrm{D}_{2}$ mixture and then be consumed by the end of the reaction (Figure 6, center panel, pink trace), but the estimated partial pressure for that gas is quite noisy because of the multiple interferences in the deconvolution process involved. This problem is more acute in the experiments with the $\mathrm{C}_{2} \mathrm{D}_{4}+\mathrm{H}_{2}$ mixtures (Figure 7), where even the values of TON reported for the light ethanes are not as reliable as in the $\mathrm{C}_{2} \mathrm{H}_{4}+\mathrm{D}_{2}$ study (Figure 6). Finally, the corresponding TONs estimated at the end of the reactions (solid bars) and the TOFs averaged over the period between 30 and 50 $\mathrm{s}$ of reaction (hatched bars) are summarized in the right panels of both figures. These data provide new information about the ethylene hydrogenation reaction, and will be discussed in more detail in the Discussion.

\section{Discussion}


Here we report the results from some of our operando studies on the hydrogenation of ethylene promoted by a $\operatorname{Pt}(111)$ single-crystal surface that combine the continuous determination of the gas composition using mass spectrometry with the simultaneous RAIRS characterization of the surface intermediates. Much of what we have seen in these studies has been reported before, and is therefore not worth discussing in great detail here. For instance, the RAIRS data show the presence of ethylidyne species on the surface during reaction, as indicated before $[16 ; 17 ; 41]$. We estimate its coverage to be only a fraction of saturation, again consistent with previous reports, and highlight the slight change in vibrational frequency of the umbrella mode of the methyl moiety [41]. Another interesting observation is that the kinetics of the reaction displays zero order in the pressure of the olefin all throughout the conversion. Our experiments were carried out in an excess of hydrogen so no kinetic dependence on the pressure of that gas was extracted, but that has been done in previous studies as well [13; 41]. Much of the preparatory work described here was directed at assessing the performance of our so-called high pressure cell: we show that our system is designed to mix the gases well with a sub-second time scale, and that the gas composition can be followed by mass spectrometry in a continuous manner throughout the conversion and reaction rates extracted as a function of reaction time. The use of mass spectrometry also affords the study of isotope scrambling reactions.

The main new results from our work refer to the latter, namely, to the study of H-D scrambling in experiments with $\mathrm{C}_{2} \mathrm{H}_{4}+\mathrm{D}_{2}$ and $\mathrm{C}_{2} \mathrm{D}_{4}+\mathrm{H}_{2}$ mixtures. The corresponding data are provided in Figures 6 and 7. This type of studies have been performed before, both on supported platinum catalysts [6; 78-83] and on a $\operatorname{Pt}(111)$ surface [13], but we here report much better quality data as 
a function of reaction time in order to extract information not previously available. Perhaps the most important observation from our work is that the ethane isotopologues formed in the hydrogenation (deuteration) reaction tend to be rich in the isotope opposite to the one added. That is, the conversion of $\mathrm{C}_{2} \mathrm{H}_{4}+\mathrm{D}_{2}$ mixtures yields lots of $\mathrm{C}_{2} \mathrm{H}_{5} \mathrm{D}$ and $\mathrm{C}_{2} \mathrm{H}_{6}$, whereas reactions with $\mathrm{C}_{2} \mathrm{D}_{4}+\mathrm{H}_{2}$ produces some $\mathrm{C}_{2} \mathrm{D}_{5} \mathrm{H}$. The extra $\mathrm{H}$ or $\mathrm{D}$ atoms in those products (respectively) must come from other ethylene molecules since they cannot be provided by the $\mathrm{D}_{2} / \mathrm{H}_{2}$ gas, implying that there must be a fast exchange on the surface among ethylene molecules without the involvement of the added $\mathrm{X}_{2}(\mathrm{X}=\mathrm{H}$ or $\mathrm{D})$. This conclusion is supported by the differences seen between the total TON and the initial TOFs: in the experiments with $\mathrm{C}_{2} \mathrm{H}_{4}+\mathrm{D}_{2}$ the TOF is larger than the TON only for $\mathrm{C}_{2} \mathrm{H}_{6}$, and with $\mathrm{C}_{2} \mathrm{D}_{4}+\mathrm{H}_{2}$ the relationship TOF $>$ TON also holds for $\mathrm{C}_{2} \mathrm{D}_{5} \mathrm{H}$ (no $\mathrm{C}_{2} \mathrm{D}_{6}$ is made in that case, though, possibly because of kinetic and/or thermodynamic isotope effect).

An alternative way to analyze the data with the aim to highlight the behavior of the isotopic composition of the products is to plot the average number of deuterium atoms per ethane molecule produced, $\mathrm{C}_{2} \mathrm{X}_{6}<\mathrm{d}>$, as a function of reaction time. This is shown in Figure 8 for both cases, for $\mathrm{C}_{2} \mathrm{H}_{4}+\mathrm{D}_{2}$ (left panel) and for $\mathrm{C}_{2} \mathrm{D}_{4}+\mathrm{H}_{2}$ (right). The $\langle\mathrm{d}\rangle$ values have been normalized to the number of deuterium atoms expected based on stoichiometric arguments to directly compare with the extent of conversion and to highlight any excess or deficit. It can be seen there that, for the first case, with the $\mathrm{C}_{2} \mathrm{H}_{4}+\mathrm{D}_{2}$ mixture, the ratio of $\langle\mathrm{d}>$ to the number of ethane molecules produced reaches a value of 2 at the end of the reaction, as expected if all the normal hydrogen atoms are retained by the hydrocarbons and not removed as HD or $\mathrm{H}_{2}$. This means that the rate of atomic hydrogen recombination on the surface must be much slower than 
any steps involving the incorporation of surface hydrogen atoms in the carbon-containing adsorbed species (the ethylene and ethyl intermediates). The slow nature of the $\mathrm{X}_{2}$ production is somewhat surprising, since independent surface-science measurements on hydrogen adsorptiondesorption rates $[51 ; 53 ; 84 ; 85]$ and on $\mathrm{H}-\mathrm{D}$ scrambling with $\mathrm{H}_{2}+\mathrm{D}_{2}$ mixtures $[50 ; 86-88]$ have indicated high conversion rates for these steps. However, most of the reported experiments have been carried out on clean $\mathrm{Pt}$, and it is known that during olefin hydrogenations the surface becomes covered with both strongly-bonded carbonaceous deposits, ethylidyne in this case as shown in Figure $4[8 ; 13 ; 16 ; 17 ; 41]$, and weakly adsorbed pi-bonded olefins $[16 ; 17 ; 33 ; 38$; 89]. It may therefore be concluded that those species inhibit molecular hydrogen adsorption, to the point that it becomes the rate-limiting step during the catalytic hydrogenation processes. A similar observation was reported in the early years of research in this area based on the lack of interconversion between para and ortho hydrogen during ethylene hydrogenation [6; 90].

For the experiments with $\mathrm{C}_{2} \mathrm{D}_{4}+\mathrm{H}_{2}$ mixtures, the right panel of Figure 8 show that the $\langle\mathrm{d}>$ at the end of the conversion reaches a value of approximately three, short of the expected number of four. We assume that this is due to the cumulative errors introduced in the deconvolution of the raw mass spectrometry data to obtain the ethane isotopologue distribution, because the cracking patterns of most of those overlap significantly in much of the mass range recorded in these experiments; otherwise this result would be in contradiction with those obtained with the $\mathrm{C}_{2} \mathrm{H}_{4}+\mathrm{D}_{2}$ mixture. On the other hand, the deviation from stoichiometry may in principle be possible if there are significant isotope effects in the relative rates of the reactions involved, something that we do not think is the case. A deficit in deuterium atoms in the final products from the conversion of $\mathrm{C}_{2} \mathrm{D}_{4}+\mathrm{H}_{2}$ mixtures would indicate a limited removal of isotopes via 
atomic hydrogen recombination steps, but even if that is the case, the contribution seems minimal given the large excess of molecular hydrogen used in the gas.

One interesting aspect deriving from these calculation of average deuterium content in the ethane produced with mixed isotope ethylene plus hydrogen mixtures is that mass balance arguments lead to the conclusion that the average number of hydrogen/deuterium atoms per ethane molecule after $100 \%$ conversion cannot be higher than the number of hydrogen/deuterium atoms in the original ethylene. Regardless, in most of the previous published studies on ethylene hydrogenation using $\mathrm{C}_{2} \mathrm{H}_{4}+\mathrm{D}_{2}$ mixtures, the reported $\langle\mathrm{d}>$ values are below two, short of the mass balance expectation, a fact that no report has ever discussed $[6 ; 13 ; 78-83]$. Lower $<\mathrm{d}>$ values may be justifiable before $100 \%$ conversion by assuming that the deficit is covered by the formation of isotope-exchanged ethylene rich on the required isotope ( $D$ with $\mathrm{C}_{2} \mathrm{H}_{4}+\mathrm{D}_{2}$ and $\mathrm{H}$ with $\mathrm{C}_{2} \mathrm{D}_{4}+\mathrm{H}_{2}$ ), and such deviations are indeed seen in our experiments, as shown in Figure 8: with $\mathrm{C}_{2} \mathrm{H}_{4}+\mathrm{D}_{2}$, the value of $\langle\mathrm{d}\rangle$ in the initial stages of the reaction starts at about one but increases steadily until reaching its final stoichiometric value of two at full conversion. Changes in isotope composition with extent of reaction were seen by us before [13], but no evidence for the accumulation of the required isotope-labeled ethylene has been provided, and we cannot do that here either, because the problem of extraction of the concentrations of all the ethylene and ethane isotopologues from the experimental data is under-defined: there are not enough masses to follow with mass spectrometry to cover all $5+7=12$ possible compounds. Nevertheless, there is no clear indication that significant amounts of isotope-exchanged ethylene are released to the gas phase in any of the reported experiments, here or elsewhere. Also, to reiterate, any deviation from the reaction stoichiometry needs to be corrected once reaching $100 \%$ conversion. 
There is clearly a piece of the puzzle missing in this analysis and all previous reports that will require independent work with other techniques.

In connection with the discussion above, it is also valuable to analyze the distribution of the isotope composition of the ethane produced as the reaction proceeds. The appropriate data are provided in the central panels of Figures 6 and 7. It is clear from those results, and from the comparisons between final TONs and initial TOFs provided in the right panels, that although these distributions do change over the course of the reaction, they do so slowly and to a limited extent. Notice in particular that they start with extensive amounts of multiply-exchanged ethanes even at the early times of the kinetic runs. In fact, the deuterium distributions are close to (although do not match) the distributions expected based on a statistical analysis (assuming no loss to $X_{2}$ production), which are shown as lines in the right panels of Figures 6 and 7. This indicates that isotope scrambling within the ethylene molecules adsorbed on the platinum surface is rapid and takes place extensively before either desorption to the gas phase or full hydrogenation to ethane. The deviations from statistical scrambling have in the past been taken as evidence for two types of mechanisms being operational for the isotope exchange and hydrogenation reactions [6], but we believe that they are more likely due to kinetic or thermodynamic isotope effects.

The dominant mechanism operational in these olefin isotope scrambling and hydrogenation systems is that initially proposed by Horiuti and Polanyi $[3 ; 6 ; 8]$, where hydrogenation from the olefin to the alkane occurs in a stepwise fashion, via the sequential incorporation of two hydrogen atoms from the surface, and where H-D exchange is explained by adding a reverse 
beta-hydride elimination step from the alkyl surface intermediate [91]. Based on that sequence, the fast isotope scrambling seen here must be interpreted as a consequence of a rapid interconversion between ethylene and surface ethyl groups. Both those steps must be faster than the second hydrogenation step, from ethyl to ethane, to allow for the multiple deuterium substitutions in the final alkane seen in the experiments. In fact, multiple H-D substitutions have been seen in the olefin itself in temperature-programmed desorption (TPD) experiments with olefins coadsorbed with deuterium $[24 ; 30 ; 34 ; 37 ; 39 ; 40 ; 92]$. Finally, the lack of a build up of deuterium-labeled ethylene molecules in the gas mixture indicates (or, at least, the lack of evidence for this suggests) that the beta-hydride elimination of ethyl groups must be faster than the reverse conversion of ethylene to ethyl. Surface-science experiments and theoretical calculations support most of these conclusions $[4 ; 37 ; 38 ; 91 ; 93-96]$. Specifically, we have reported activation energies of approximately 6,13 , and $19 \mathrm{kcal} / \mathrm{mol}$ for the ethylene to ethyl, ethyl to ethylene, and ethyl to ethane, respectively [25], and Vlachos and coworkers estimated values of 15, 28, and $24 \mathrm{kcal} / \mathrm{mol}$ for those same reactions [97] (larger absolute values but similar trends). The one discrepancy here is the fact that the barrier for the beta-hydride elimination step from adsorbed ethyl species is higher than the reverse hydrogenation of ethylene to ethyl, yet the rates seem to follow the opposite order. We explain this by the second-order nature of the hydrogenation steps: the rate for ethyl formation may be low because of the potential low coverage of atomic hydrogen on the surface or because the possible hindrance in the diffusion of the hydrogen surface atoms by the other adsorbed species [8; 34]. In fact, this may also be the reason why the hydrogen or deuterium atoms released from adsorbed ethylene to the surface during the isotope scrambling do not easily recombine and desorb as $\mathrm{X}_{2}$, as mentioned before; that reaction is second order on the coverage of atomic hydrogen on the 
surface. Ultimately, this low coverage of atomic hydrogen/deuterium on the surface of the platinum catalyst during olefin hydrogenations and its implications to the kinetics of these reactions is the observation that we want to highlight in the present studies.

\section{Conclusions}

In this report we discuss the use of an instrument combining typical UHV techniques and a socalled high-pressure cell for the study of olefin hydrogenation reactions catalyzed by a $\operatorname{Pt}(111)$ single-crystal surface. Our equipment is in many ways similar to that of others, except that we have chosen to use mass spectrometry instead of gas chromatography for the detection and quantitation of the gas mixture during reaction, and reflection-absorption infrared spectroscopy (RAIRS) for the characterization of the species adsorbed on the surface under operando conditions, that is, as the catalytic conversion takes place. From the experimental point of view, our setup displays a number of advantages, including: (1) the ability to follow reaction kinetics continuously and with good precision, affording the calculation of reaction rates as a function of time to identify possible subtle changes; (2) the capability to use isotope labeling, which permits the study of H-D scrambling steps; (3) a fast response to changes in the system, providing the ability to follow chemical changes with a sub-second time resolution; and (4) the possibility to characterize the changes taking place on the surface, in our case in the strongly bonded carbonaceous deposits (alkylidynes) present on the surface, by RAIRS as the catalytic run

progresses, simultaneously with the kinetic measurements. RAIRS can also be used to corroborate the composition of the gas estimated by mass spectrometry. 
In terms of the chemistry of ethylene hydrogenation promoted by $\operatorname{Pt}(111)$, we report zero-order kinetics with respect to the pressure of the olefin all throughout the course of the reaction, until completion, at least with mixtures rich in hydrogen. It was also observed that the ethylidyne moieties that form on the surface upon exposure to the ethylene gas persist during the reaction, but at a coverage much lower than that seen under vacuum; it appears that under steady-state reaction conditions a significant amount of those species $(\sim 80 \%)$ are hydrogenated and removed from the surface, so the olefin hydrogenation process occurs on a catalyst with a significant fraction of its metal surface uncovered (or. more likely, covered with more weakly- and reversibly-adsorbed species, namely, pi-bonded olefins). The adsorbed alkylidyne is also modified slightly when in equilibrium with the reaction gas mixture, a fact manifested by a slight shift in the position of the vibrational peak associated with the symmetric deformation mode of the terminal methyl group.

Finally, experiments both with normal ethylene plus $\mathrm{D}_{2}$ and with perdeuteroethylene plus normal $\mathrm{H}_{2}$ gas mixtures were used to follow the hydrogen exchange within the organic molecules. A distribution of isotopologues of ethane was detected in both cases. The main product was that expected by the straight addition of two $\mathrm{H}$ or $\mathrm{D}$ atoms to the reactant, but a significant fraction of the products displayed other degrees of substitutions. Ethane molecules with all possible number of isotope substitutions were seen with $\mathrm{C}_{2} \mathrm{H}_{4}+\mathrm{D}_{2}$, in a TON distribution approximately logarithmic versus the number of deuterium atoms for isotopologues beyond $\mathrm{C}_{2} \mathrm{H}_{4} \mathrm{D}_{2}$. In the case of the $\mathrm{C}_{2} \mathrm{D}_{4}+\mathrm{H}_{2}$ mixture, some $\mathrm{C}_{2} \mathrm{D}_{5} \mathrm{H}$ but no $\mathrm{C}_{2} \mathrm{D}_{6}$ was seen, indicating the limited degree of isotope scrambling possible under our reaction conditions. One new observation from our 
work is the fact that although the relative ratios among the rates for the formation of the different isotopologues in the experiments with mixed-isotope feedstocks are approximately constant in the initial stages of the reaction, they do change with the extent of conversion. In particular, the isotopologues enriched in the hydrogen isotope not provided in the initial mixture $\left(\mathrm{H}\right.$ for $\mathrm{C}_{2} \mathrm{H}_{4}+$ $D_{2}$ or $\mathrm{D}$ for $\mathrm{C}_{2} \mathrm{D}_{4}+\mathrm{H}_{2}$ ) peak early, a result that is counterintuitive and that suggests that some ethylene may dehydrogenate or H-D exchange fast and release the required hydrogen atoms on the surface at the start of the kinetic runs. More work is required to better explain this behavior. In the end, though, the average hydrogen isotope composition is that of the stoichiometry of the gas mixture, specifically, the final $\mathrm{H}$ :D ratio with $\mathrm{C}_{2} \mathrm{H}_{4}+\mathrm{D}_{2}$ is $4: 2$, indicating that hydrogen recombination on the surface is much slower than any of the hydrocarbon conversion steps.

\section{Acknowledgements}

Funds for this project were provided by the US National Science Foundation, Division of Chemistry, under Contract No. CHE-1359668. 


\section{References}

[1] P. Sabatier, J.-B. Senderens, C. R. Hebd. Seances Acad. Sci. (1897) 1358-1361.

[2] Z. Ma, F. Zaera, in: Encyclopedia of Inorganic and Bioinorganic Chemistry, R. A. Scott (Ed.), John Wiley \& Sons, Ltd, Chichester, 2014, p. eibc0079.

[3] I. Horiuti, M. Polanyi, Trans. Faraday Soc. 30 (1934) 1164-1172.

[4] I. Lee, F. Delbecq, R. Morales, M. A. Albiter, F. Zaera, Nat. Mater. 8 (2009) 132-138.

[5] F. Zaera, J. Phys. Chem. B 106 (2002) 4043-4052.

[6] G. C. Bond, Metal-Catalysed Reactions of Hydrocarbons, Springer, New York, 2005.

[7] D. C. Tang, K. S. Hwang, M. Salmeron, G. A. Somorjai, J. Phys. Chem. B 108 (2008) 13300-13306.

[8] F. Zaera, Phys. Chem. Chem. Phys. 15 (2013) 11988-12003.

[9] Y. Li, D. Zakharov, S. Zhao, R. Tappero, U. Jung, A. Elsen, P. Baumann, R. G. Nuzzo, E. A. Stach, A. I. Frenkel, Nat. Commun. 6 (2015).

[10] F. Zaera, Langmuir 12 (1996) 88-94.

[11] A. L. Marsh, G. A. Somorjai, Top. Catal. 34 (2005) 121-128.

[12] U. Jung, A. Elsen, Y. Li, J. G. Smith, M. W. Small, E. A. Stach, A. I. Frenkel, R. G. Nuzzo, ACS Catal. 5 (2015) 1539-1551.

[13] F. Zaera, G. A. Somorjai, J. Am. Chem. Soc. 106 (1984) 2288-2293.

[14] A. Wieckowski, S. D. Rosasco, G. N. Salaita, A. Hubbard, B. E. Bent, F. Zaera, D. Godbey, G. A. Somorjai, J. Am. Chem. Soc. 107 (1985) 5910-5920.

[15] T. P. Beebe, Jr., J. T. Yates, Jr., J. Am. Chem. Soc. 108 (1986) 663-671. 
[16] P. S. Cremer, X. Su, Y. R. Shen, G. A. Somorjai, J. Am. Chem. Soc. 118 (1996) 29422949.

[17] T. Ohtani, J. Kubota, J. N. Kondo, C. Hirose, K. Domen, J. Phys. Chem. B 103 (1999) $4562-4565$.

[18] B. Brandt, J.-H. Fischer, W. Ludwig, J. Libuda, F. Zaera, S. Schauermann, H.-J. Freund, J. Phys. Chem. C 112 (2008) 11408-11420.

[19] H. Molero, D. Stacchiola, W. T. Tysoe, Catal. Lett. 101 (2005) 145-149.

[20] W. Wasylenko, H. Frei, J. Phys. Chem. B 109 (2005) 16873-16878.

[21] F. Zaera, Surf. Sci. 219 (1989) 453-466.

[22] F. Zaera, J. Am. Chem. Soc. 111 (1989) 4240-4244.

[23] L. P. Wang, W. T. Tysoe, R. M. Ormerod, R. M. Lambert, H. Hoffmann, F. Zaera, J. Phys. Chem. 94 (1990) 4236-4239.

[24] F. Zaera, J. Phys. Chem. 94 (1990) 5090-5095.

[25] F. Zaera, J. Phys. Chem. 94 (1990) 8350-8355.

[26] H. Hoffmann, P. R. Griffiths, F. Zaera, Surf. Sci. 262 (1992) 141-150.

[27] F. Zaera, Acc. Chem. Res. 25 (1992) 260-265.

[28] F. Zaera, J. Mol. Catal. 86 (1994) 221.

[29] F. Zaera, N. Bernstein, J. Am. Chem. Soc. 116 (1994) 4881.

[30] T. V. W. Janssens, F. Zaera, Surf. Sci. 344 (1995) 77-84.

[31] A. Loaiza, M. Xu, F. Zaera, J. Catal. 159 (1996) 127-139.

[32] F. Zaera, T. V. W. Janssens, H. Öfner, Surf. Sci. 368 (1996) 371-376.

[33] H. Öfner, F. Zaera, J. Phys. Chem. B 101 (1997) 396-408.

[34] T. V. W. Janssens, D. Stone, J. C. Hemminger, F. Zaera, J. Catal. 177 (1998) 284-295. 
[35] F. Zaera, C. R. French, J. Am. Chem. Soc. 121 (1999) 2236-2243.

[36] F. Zaera, D. Chrysostomou, Surf. Sci. 457 (2000) 71-88.

[37] F. Zaera, D. Chrysostomou, Surf. Sci. 457 (2000) 89-108.

[38] F. Zaera, Appl. Catal. A 229 (2002) 75-91.

[39] R. Morales, F. Zaera, J. Phys. Chem. B 110 (2006) 9650-9659.

[40] R. Morales, F. Zaera, J. Phys. Chem. C 111 (2007) 18367-18375.

[41] A. Tilekaratne, J. P. Simonovis, M. F. López Fagúndez, M. Ebrahimi, F. Zaera, ACS Catal. 2 (2012) 2259-2268.

[42] D. W. Blakely, E. I. Kozak, B. A. Sexton, G. A. Somorjai, J. Vac. Sci. Technol. 13 (1976) 1091-1096.

[43] C. T. Campbell, Adv. Catal. 36 (1989) 1-54.

[44] J. A. Rodriguez, D. W. Goodman, Surf. Sci. Rep. 14 (1991) 1-107.

[45] Z. Ma, F. Zaera, Surf. Sci. Rep. 61 (2006) 229-281.

[46] W. Tysoe, in: Model Systems in Catalysis, R. Rioux (Ed.), Springer New York, 2010, pp. $1-28$

[47] F. M. Hoffmann, Surf. Sci. Rep. 3 (1983) 107-192.

[48] F. Zaera, Int. Rev. Phys. Chem. 21 (2002) 433-471.

[49] F. Zaera, Chem. Soc. Rev. 43 (2014) 7624 - 7663.

[50] M. Salmeron, R. J. Gale, G. A. Somorjai, J. Chem. Phys. 67 (1977) 5324-5334.

[51] A. T. Gee, B. E. Hayden, C. Mormiche, T. S. Nunney, J. Chem. Phys. 112 (2000) 76607668.

[52] M. Johansson, O. Lytken, I. Chorkendorff, J. Chem. Phys. 128 (2008) 034706/034701034706/034711. 
[53] I. M. N. Groot, A. W. Kleyn, L. B. F. Juurlink, J. Phys. Chem. C 117 (2013) 9266-9274.

[54] J. M. Thomas, W. J. Thomas, Introduction to the Principles of Heterogeneous Catalysis, Academic Press, London, 1967.

[55] B. C. Gates, J. R. Katzer, G. C. A. Schuit, Chemistry of Catalytic Processes, McGrawHill, New York, 1979.

[56] Z. Paál, P. G. Menon (Eds.), Hydrogen Effects in Catalysis: Fundamentals and Practical Applications, New York, 1988.

[57] F. Zaera, H. Hoffmann, P. R. Griffiths, J. Electron Spectrosc. Relat. Phenom. 54/55 (1990) 705-715.

[58] I. Lee, M. K. Nguyen, T. H. Morton, F. Zaera, J. Phys. Chem. C 112 (2008) 1411714123.

[59] J. Wilson, H. Guo, R. Morales, E. Podgornov, I. Lee, F. Zaera, Phys. Chem. Chem. Phys. 9 (2007) 3830-3852.

[60] J. C. F. Rodríguez-Reyes, A. V. Teplyakov, S. D. Brown, Surf. Sci. 604 (2010) 20432054.

[61] D. W. Goodman, R. D. Kelley, T. E. Madey, J. T. Yates, Jr., J. Catal. 63 (1980) 226-234.

[62] C. T. Campbell, M. T. Paffett, Surf. Sci. 139 (1984) 396-416.

[63] B. Bartlett, C. Soto, R. Wu, W. T. Tysoe, Catal. Lett. 21 (1993) 1-10.

[64] G. H. Zhu, J. Y. Han, D. Y. Zemlyanov, F. H. Ribeiro, J. Am. Chem. Soc. 126 (2004) 9896-9897.

[65] R. G. Greenler, J. Chem. Phys. 44 (1966) 310-315.

[66] Y. J. Chabal, Surf. Sci. Rep. 8 (1988) 211-357. 
[67] G. Socrates, Infrared Characteristic Group Frequencies: Tables and Charts, 2nd, Wiley, Chichester, 1994.

[68] M. Ebrahimi, J. P. Simonovis, F. Zaera, J. Phys. Chem. Lett. 5 (2014) 2121-2125.

[69] J. Kubota, T. Ohtani, J. N. Kondo, C. Hirose, K. Domen, Appl. Surf. Sci. 121-122 (1997) $548-551$.

[70] J. D. Krooswyk, I. Waluyo, M. Trenary, ACS Catal. 5 (2015) 4725-4733.

[71] P. Skinner, M. W. Howard, I. A. Oxton, S. F. A. Kettle, D. B. Powell, N. Sheppard, J. Chem. Soc., Faraday Trans. II 77 (1981) 1203-1215.

[72] M. A. Chesters, E. M. McCash, Surf. Sci. Lett. 187 (1987) L639-L641.

[73] S. B. Moshin, M. Trenary, H. J. Robota, Chem. Phys. Lett. 154 (1989) 511-515.

[74] P. Cremer, C. Stanners, J. W. Niemantsverdriet, Y. R. Shen, G. Somorjai, Surf. Sci. 328 (1995) 111-118.

[75] S. M. Davis, F. Zaera, B. Gordon, G. A. Somorjai, J. Catal. 92 (1985) 240-246.

[76] F. Zaera, Catal. Lett. 91 (2003) 1-10.

[77] Z.-J. Zhao, L. V. Moskaleva, H. A. Aleksandrov, D. Basaran, N. Rösch, J. Phys. Chem. C 114 (2010) 12190-12201.

[78] G. C. Bond, Trans. Faraday Soc. 52 (1956) 1235-1244.

[79] G. C. Bond, J. J. Phillipson, P. B. Wells, J. M. Winterbottom, Trans. Faraday Soc. 60 (1964) 1847-1864.

[80] J. Horiuti, K. Miyahara, Hydrogenation of Ethylene on Metallic Catalysts, Washington, National Bureau of Standards, 1968.

[81] D. Briggs, J. Dewing, A. G. Burden, R. B. Moyes, P. B. Wells, J. Catal. 65 (1980) 31-35.

[82] S. A. Goddard, R. D. Cortright, J. A. Dumesic, J. Catal. 137 (1992) 186-198. 
[83] H. Yoshitake, Y. Iwasawa, J. Phys. Chem. 96 (1992) 1329-1334.

[84] K. Christmann, G. Ertl, T. Pignet, Surf. Sci. 54 (1976) 365-392.

[85] S. K. Jo, Surf. Sci. 635 (2015) 99-107.

[86] S. L. Bernasek, G. A. Somorjai, J. Chem. Phys. 62 (1974) 3149-3161.

[87] M. Montano, K. Bratlie, M. Salmeron, G. A. Somorjai, J. Am. Chem. Soc. 128 (2006) $13229-13234$.

[88] M. Johansson, O. Lytken, I. Chorkendorff, Top. Catal. 46 (2007) 175-187.

[89] H. Öfner, F. Zaera, J. Am. Chem. Soc. 124 (2002) 10982-10983.

[90] A. Farkas, L. Farkas, J. Am. Chem. Soc. 60 (1938) 22-28.

[91] F. Zaera, J. Am. Chem. Soc. 111 (1989) 8744-8745.

[92] I. Lee, F. Zaera, J. Phys. Chem. B 109 (2005) 2745-2753.

[93] D. Chrysostomou, C. French, F. Zaera, Catal. Lett. 69 (2000) 117-128.

[94] F. Zaera, Mol. Phys. 100 (2002) 3065-3073.

[95] F. Zaera, Top. Catal. 34 (2005) 129-141.

[96] F. Zaera, J. Mol. Catal. A: Chem. 228 (2005) 21-26.

[97] Y. Chen, D. G. Vlachos, J. Phys. Chem. C 114 (2010) 4973-4982. 


\section{Figure Captions}

Figure 1. Gas-mixture mass spectra in the $0-50 \mathrm{amu}$ range during the catalytic hydrogenation of ethylene promoted by a $\mathrm{Pt}(111)$ single-crystal surface, taken at different reaction times. In this case the initial mixture is composed of 2 Torr of $\mathrm{C}_{2} \mathrm{H}_{4}$ and 50 Torr of $\mathrm{H}_{2}$, and the catalyst is held at a constant temperature of $300 \mathrm{~K}$. The conversion of ethylene to ethane is mainly manifested by the growth of the peaks at 29 and $30 \mathrm{amu}$.

Figure 2. Typical kinetic data obtained for the catalytic conversion of ethylene plus hydrogen to ethane promoted by $\mathrm{Pt}(111)$. Left: raw mass-spectrometry signals for 26, 27, 29, and $30 \mathrm{amu}$ as a function of reaction time. Center: time-resolved data for ethylene and ethane, in turnover numbers $(\mathrm{TON}=$ number of molecules consumed or produced per Pt surface atom), estimated by deconvolution of the data on the left. Also provided, as solid symbols, are results from measurements using the infrared absorption spectroscopy data in Figure 3. Right: Turnover frequencies $(\mathrm{TOF}=\mathrm{TON} / \mathrm{s})$ calculated via numeric derivatization of the data in the center panel. The time evolution of the ethylene data mirrors that of ethane, and the TOFs remain approximately constant throughout most of the conversion.

Figure 3. Infrared absorption spectra of the gas-phase reaction mixture as a function of reaction time. The data were acquire by using the reflection-absorption infrared spectroscopy (RAIRS) setup in our cell, designed to follow the fate of surface species, to show that it can also be used to analyze the gas phase, and to confirm the kinetic data recorded 
with the mass spectrometer. The two panels correspond to spectra taken using p(left) and s- (right) polarized light. The two sets are nearly identical, as expected.

Figure 4. RAIRS traces for the surface intermediates adsorbed on the $\operatorname{Pt}(111)$ surface as a function of reaction time during the conversion of ethylene with hydrogen. Each trace corresponds to the difference of data acquired with p- minus s-polarized light, a calculation done to eliminate the components originating from absorption by the gasphase species and to highlight the information from the adsorbed species. The main peak, seen at approximately $1340 \mathrm{~cm}^{-1}$, corresponds to the symmetric deformation (umbrella) mode of ethylidyne.

Figure 5. Summary of the information on the peak intensity (solid red circles and left scale, reported as surface coverage after appropriate calibration) and peak position (open blue squares, right scale) for the signal corresponding to the methyl umbrella mode of ethylidyne. The decrease in intensity over time indicates removal of some of the surface species, an evolution that also accounts for the blue shift of the peak.

Figure 6. Kinetic data for the conversion of normal ethylene $\left(\mathrm{C}_{2} \mathrm{H}_{4}\right)$ with deuterium gas $\left(\mathrm{D}_{2}\right)$ on a Pt(111) surface precovered with a saturation layer of propylidyne. Left: Raw massspectrometry signals versus time for all masses in the range from 26 to 36 amu. Center: Time evolution of all isotopologues of ethane, calculated via the deconvolution of the raw data. Also shown is a trace for $\mathrm{C}_{2} \mathrm{H}_{3} \mathrm{D}$. Right: Final TONs (solid bars) and initial TOFs (hatched bars) as a function of the number of deuterium 
atom substitutions in the ethane product. Also shown is the distribution expected based on a pure statistical scrambling of an infinite pool of $\mathrm{H}$ and $\mathrm{D}$ atoms in a $\mathrm{H}: \mathrm{D}=$ 2:1 ratio. The experimental results approach (although do not fully reach) that statistical limit.

Figure 7. Similar kinetic data to those reported in Figure 6 but from an experiments with a $\mathrm{C}_{2} \mathrm{D}_{4}+\mathrm{H}_{2}$ gas mixture. The statistical trace provided in the right panel now corresponds to a $\mathrm{H}: \mathrm{D}=1: 2$ ratio.

Figure 8. Conversion fraction ( $\mathrm{F}_{\text {Conversion, }}$ blue dashed lines), average number of deuterium atoms per ethane molecule produced $(<\mathrm{d}\rangle$, red solid traces; numbers divided by 2 and 4 in the left and right panels, respectively), and ratios between those two quantities (green dotted lines), all as a function of reaction time, for the experiments in Figures 6 and 7, namely, with $\mathrm{C}_{2} \mathrm{H}_{4}+\mathrm{D}_{2}$ (left panel) and $\mathrm{C}_{2} \mathrm{D}_{4}+\mathrm{H}_{2}$ (right) gas mixtures. One of the key results seen in this figure is that the final value of $\langle\mathrm{d}\rangle$ is that expected by the stoichiometry of the ethylene hydrogenation reaction, indicating no loss of isotopes to what must be a much slower hydrogen recombination reaction. 


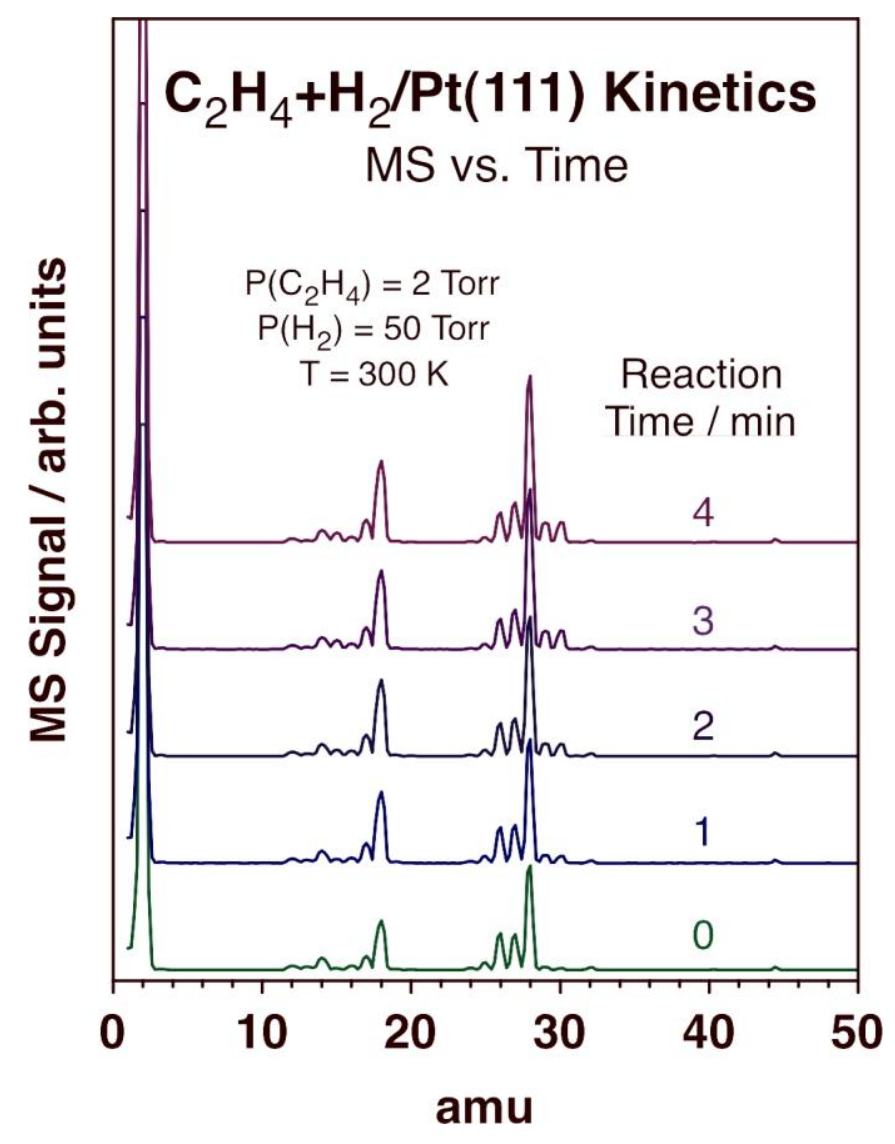

Figure 1 


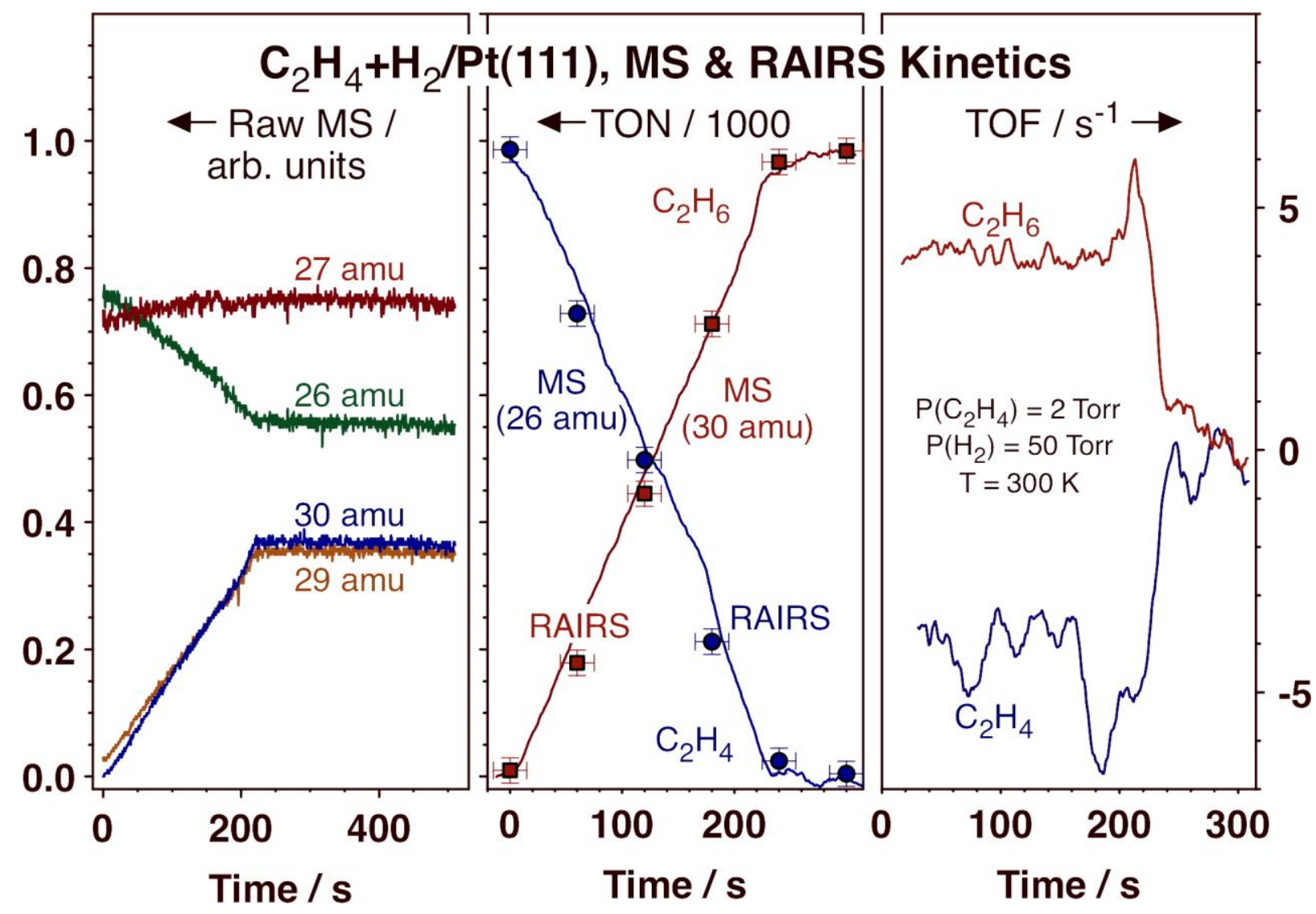

Figure 2 


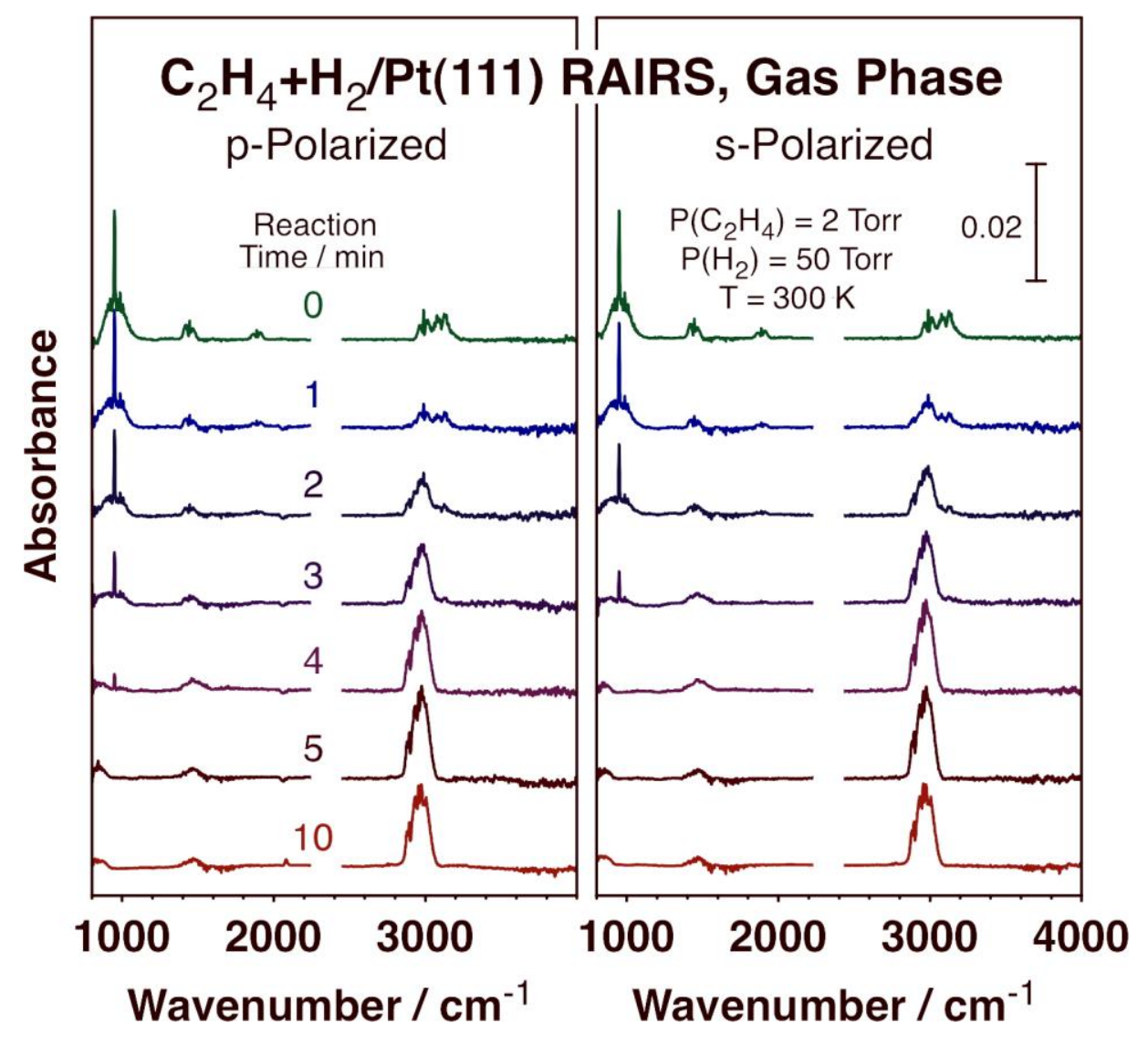

Figure 3 


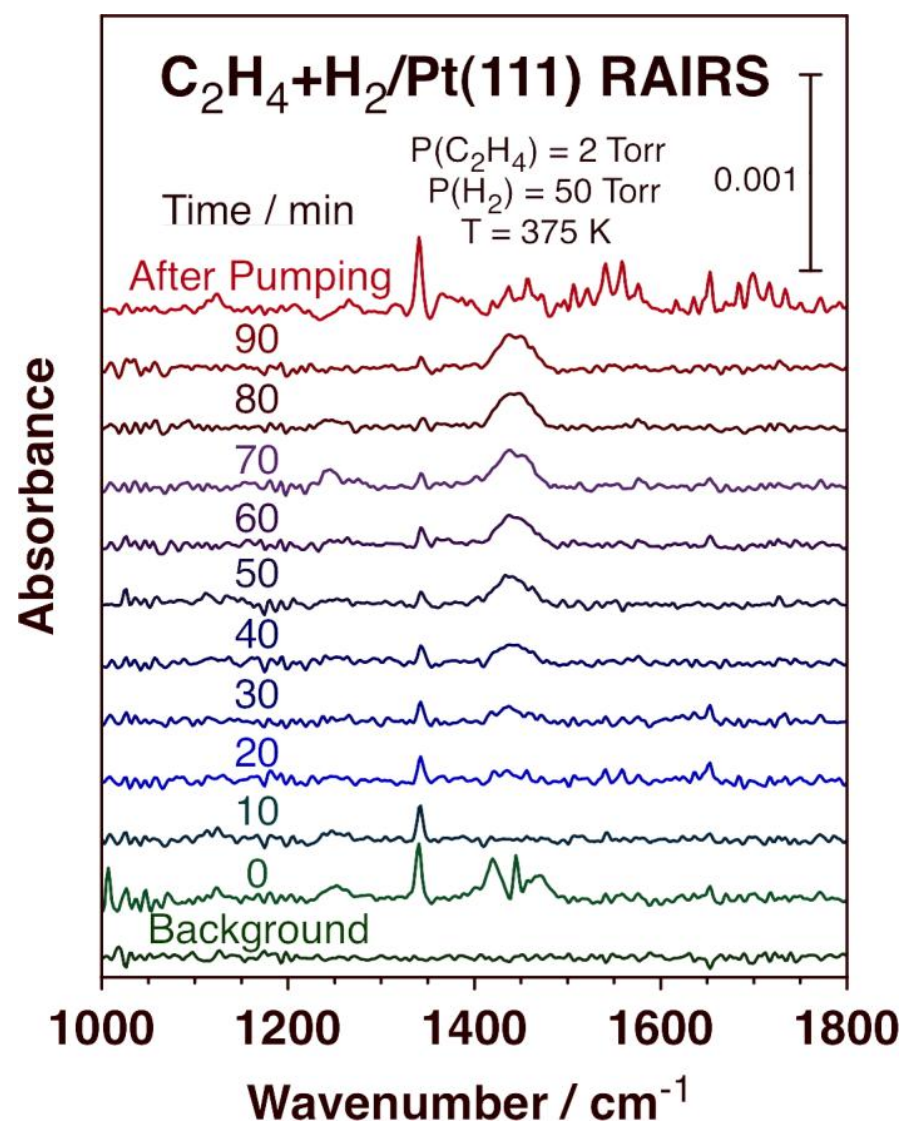

Figure 4 


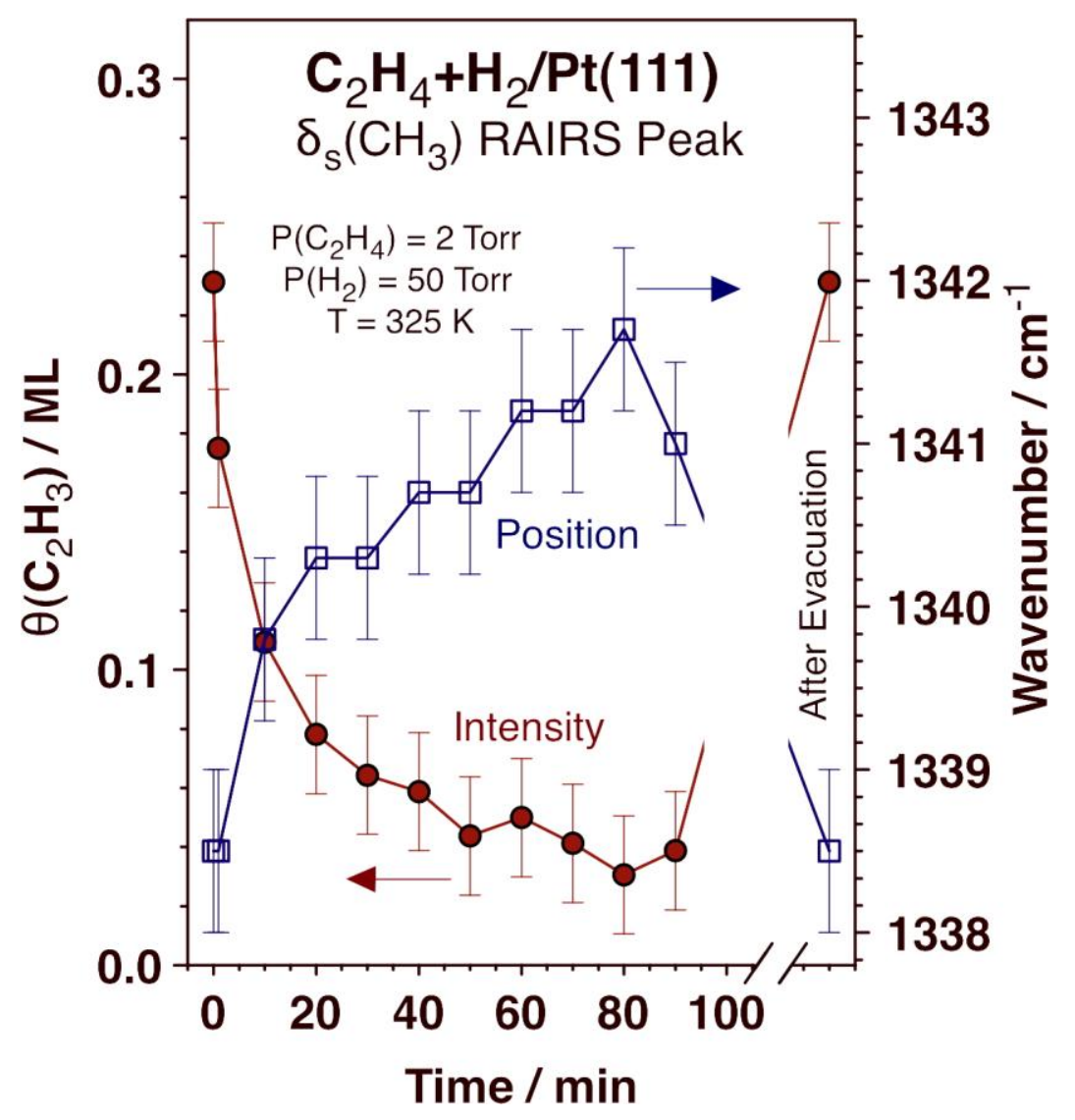

Figure 5 


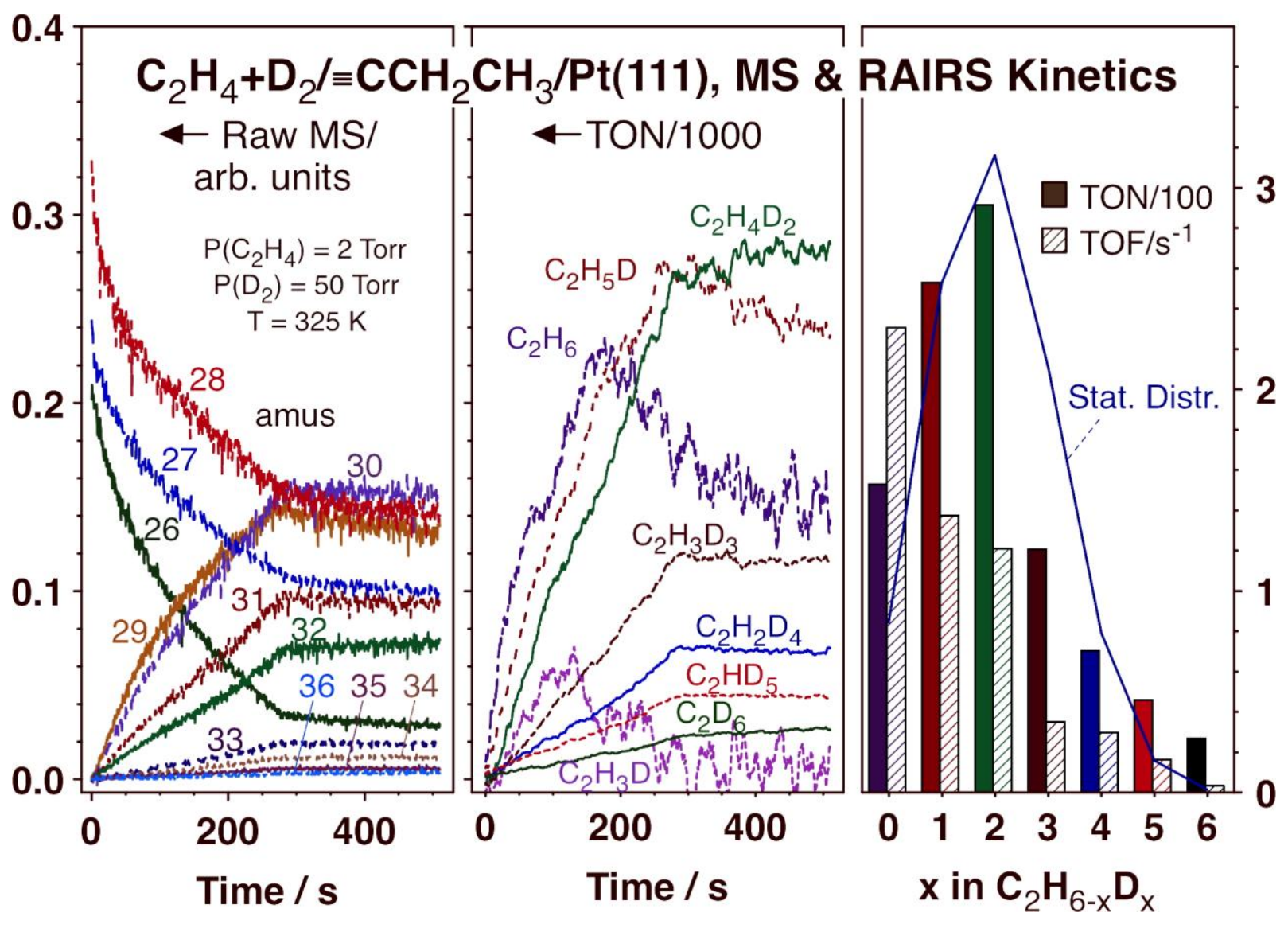

Figure 6 


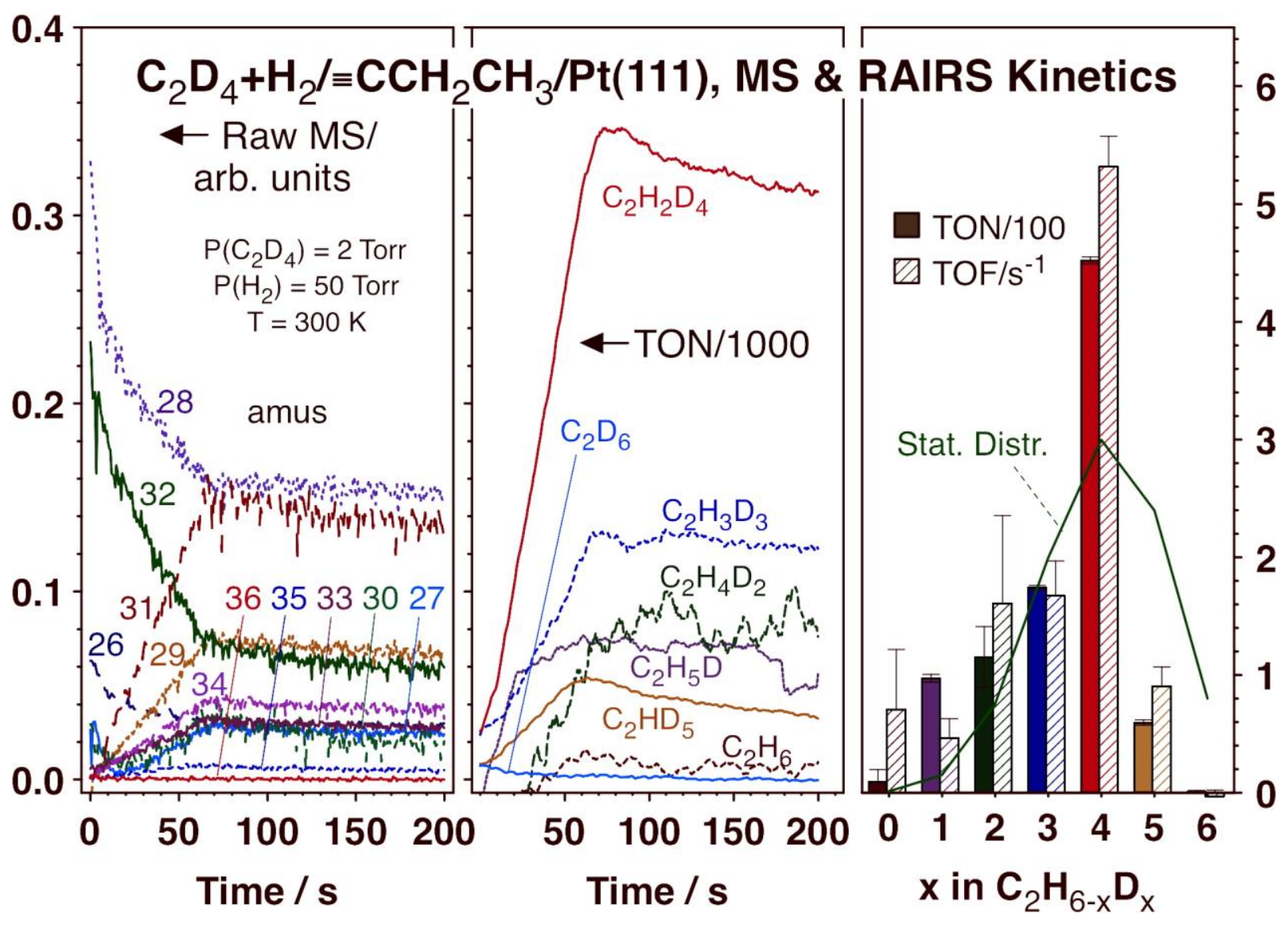

Figure 7 


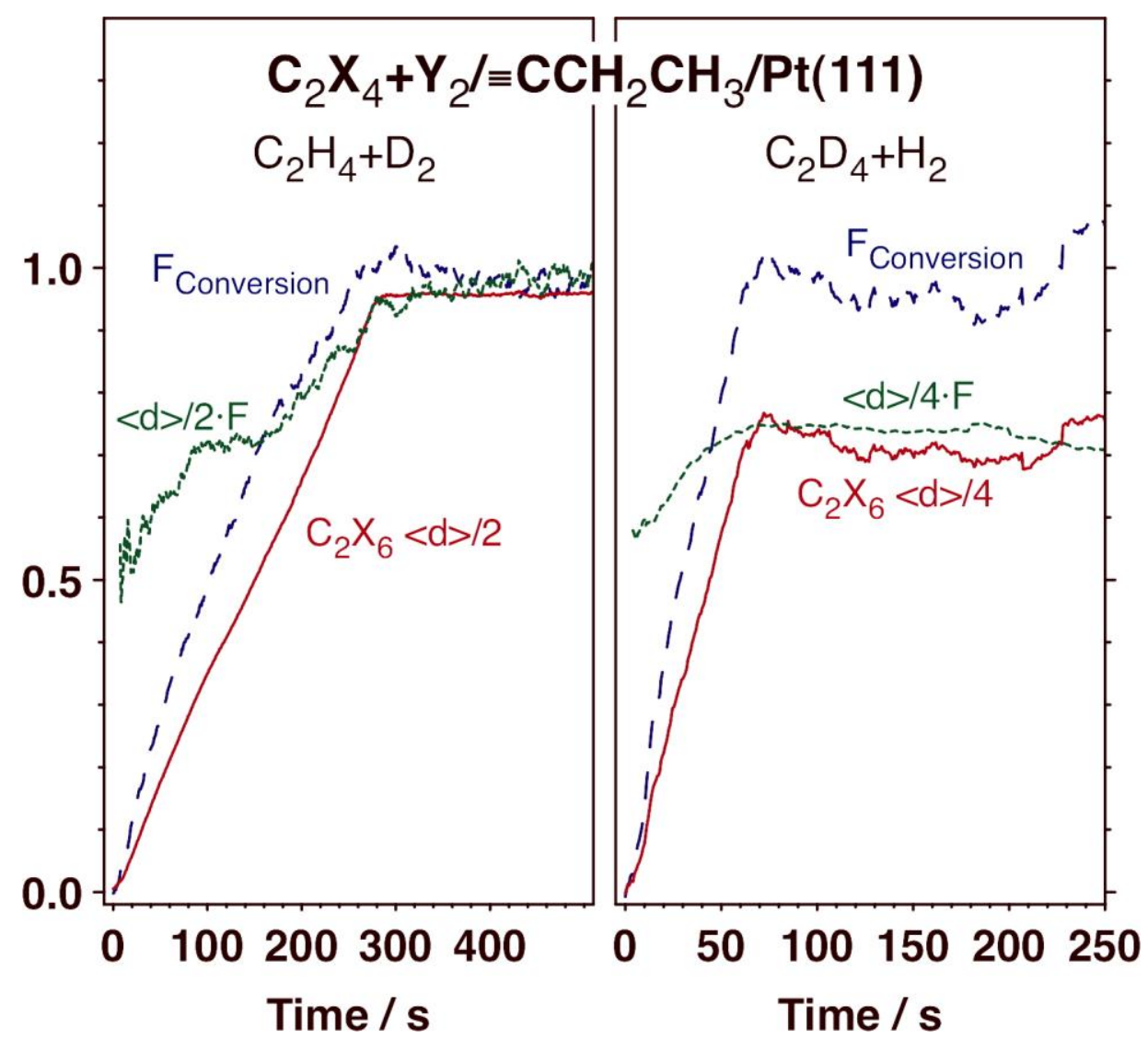

Figure 8 


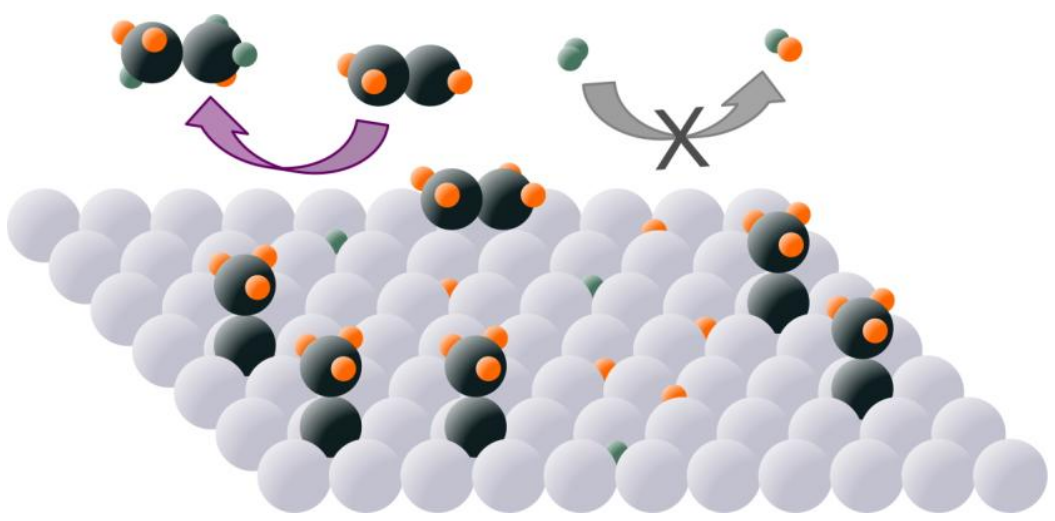

Graphical Abstract 